\title{
INFLUENCE OF BIOMASS MOISTURE CONTENT ON PELLET PROPERTIES - REVIEW
}

\author{
Nicoleta Ungureanu ${ }^{1}$, Valentin Vladut ${ }^{2}$, Gheorghe Voicu ${ }^{1}$, \\ Mirela-Nicoleta Dinca ${ }^{1}$, Bianca-Stefania Zabava ${ }^{1}$ \\ ${ }^{1}$ University Politehnica of Bucharest, Romania; ${ }^{2}$ National Institute of Research-Development for \\ Machines and Installations Designed to Agriculture and Food Industry, Romania \\ nicoletaung@yahoo.com,valentin_vladut@yahoo.com,ghvoicu_2005@yahoo.com, \\ mirela_dilea@yahoo.com, bianca.dragoiu@yahoo.com
}

\begin{abstract}
Seeking to become more climate-friendly and less energy-consuming, the European Union has pledged to cut its greenhouse gas emissions and milestones to achieve this are set to $20 \%$ by $2020,40 \%$ by $2030,60 \%$ by 2040 and $80 \%$ by 2050 . Due to its abundance, biomass is gaining more and more importance both for the production of thermal energy by direct combustion or gasification of vegetal materials, for electricity and for the production of biofuels. Direct combustion of biomass generates $\mathrm{CO}_{2}$, but the process is neutral in terms of greenhouse gas emissions, because the same amount of $\mathrm{CO}_{2}$ was absorbed by plants from the air during their life cycle. Ecological solid fuels such as pellets have become rapidly a viable alternative to fossil fuels, due to their high energy content, which makes them suitable for use by both small households and industrial consumers. Pellets are obtained from a variety of raw materials such as: agricultural residues, energy crops, forestry and wood residues, used exclusively or mixed and having different physical-chemical properties. This paper presents a summary of literature on the effect of the moisture content on the properties of pellets obtained from various types of biomass. Moisture content of raw material is one of the most important factors that influence negatively the properties of pellets, such as bulk density or mechanical durability during storage and transportation. Energy consumption increases during pelletizing of high moisture biomass, as moisture is a lubricant that lowers friction in the die. Other studies found a positive correlation between pellets durability and optimal moisture $(10 \%)$, because water together with the die temperature, pressure and chemical composition of raw material acts like a binding agent that increases pellet quality. Pellets with $5 \%$ moisture have low strength, become brittle, and large amounts of dust are produced during their storage and transportation. Moisture higher than $15 \%$ damages pellets during storage.
\end{abstract}

Keywords: biomass, climate-friendly, moisture, compression, pellets.

\section{Introduction}

The high levels of carbon dioxide, global warming caused by increased emissions of greenhouse gases, the need to generate thermal and electrical energy, and the rising cost of fossil fuels have generated a growing industry in Europe, Canada and the United States, focused on the production of energy through the use of renewable sources.

Biomass comprises compounds resulting from the photosynthesis processes and due to its carbon content could produce energy by heat or chemical processes [1]. In a strict sense, agricultural biomass includes secondary products from the plants cultivated such as: straws, corn cobs, stalks (sun flower, soy), leaves (beet), pods (soy, beans), shells (walnuts, peanuts), pips (plum, peach, apricot) and manure from animal farms. Besides the agricultural biomass sources there are the forestry ones: primary and secondary material from exploiting forests and resinous and deciduous plantations [2].

Raw biomass is characterized by heterogeneous size and shape of particles, high moisture content and low energy density which makes it difficult to use as solid fuel. To increase its density, the biomass is compressed into pellets using a mechanical process in which pressure is applied to the biomass to crush its cellular structure [3].

Pelletizing has provided a technology to obtain lower moisture, dense and uniform biofuels, with higher effective heating value and uniform shape, and a clear burning and reduction of ashes compared to raw biomass [4-6]. Thus, pellets can be used in different energy conversion systems, including household stoves, boilers and power plants [5]. Pelletizing also reduces transportation costs and provides better handling and feeding of biomass with less dust formation [7]. However, a challenge during the storage and transport of pellets is the loss of their mechanical integrity, which can lead to high levels of dust, increased risks of fire and explosions and poses a health hazard to workers. Higher dust levels might also cause heat generation in stockpiles by microbial attack [8].

The use of wood pellets for energy generation was first established in countries with large forest industry sector, such as Sweden, Austria and the USA [9; 10]. In Europe, the production of biomass 
pellets has increased in recent years, mainly due to the policies and targets to become more climatefriendly and to reduce the emissions of carbon dioxide into the atmosphere by substitution of fossil fuels with renewable fuels. The European Union has set targets of raising the share of its energy consumption produced from renewable resources to $20 \%$ by $2020,40 \%$ by $2030,60 \%$ by 2040 and $80 \%$ by 2050 .

The pellet market has been growing in Europe through the availability of residues and roundwood (production of pellets) in combination with supporting programs for residential heating, district heating and large scale power productions (consumption of pellets) [11].

Like other biomass feedstock, pellets are carbon neutral, because the carbon released during their combustion is taken up in the re-growth of the biomass used to produce them. End-consumers are mainly concerned about the energy content of pellet, the emissions generated by pellet combustion and the effects of using pellets in combustion equipments. Emissions and low-quality solid biofuels can damage the combustion equipments by producing slagging, corrosion and poor process control [12].

\section{Materials and methods}

Pelletizing consists of extrusion of raw biomass through a ring or flat die with $6-8 \mathrm{~mm}$ holes under the pressure applied by two or more rollers. The friction between biomass and the holes walls results in increased pressure and temperature, helping the lignin plasticize and glue the biomass particles. Pellets exiting the die are then cut down to a suitable length and cooled before packing [5].

Pelletizing depends on the moisture content of the raw biomass density, particle size, fiber strength, biomass lubricating characteristics and the presence of natural binders. High temperature steam is sometimes used in pelletizing operations to activate natural binders and lubricants in biomass. Water can also be added during the pelletizing stage for a similar but less pronounced effect.

Forest and sawmill residues, agricultural crop residues, and energy crops can be densified into pellets. Biomass pellets are 20-30 mm in length with broken ends, moisture content of 5-10\% [13], typical unit densities between $1000-1400 \mathrm{~kg} \cdot \mathrm{m}^{-3}$ and bulk densities of $650-700 \mathrm{~kg} \cdot \mathrm{m}^{-3}$ [3]. Pellets with high quality contain less than 0.7-1\% mineral ash and fine powders and are mechanically durable (less than $2.5 \%$ are broken into finer particles after each handling) [14].

Biomass by its nature is a hygroscopic material. Generally, field straws have lower moisture content than woody biomass. Moisture content of raw material is one of the most important factors that influence negatively the properties of pellets, such as the bulk density or mechanical durability during storage and transportation. Biomass pellets are very susceptible to moisture uptake from the surrounding environment, so it is very important to ensure watertight storage facilities. Pellets with satisfying quality must have low water impermeability in order to be stored for a long period without water absorption [15]. The moisture content of pellets should be $11-13 \%$ for storage over four months [16]. Moisture is a major inconvenience in the use of biomass as alternative fuel, because it requires a large quantity of heat for evaporation, thus leading to a major inferior calorific power [17]. Hence, the higher the moisture content, the lower the net calorific value of the biofuel pellet presented for combustion [18].

Standardization is a good tool for quality control of pellet production. The pellet quality parameters most frequently included in the standards and recommendations of different countries are the pellet size (diameter, length, and/or length/diameter ratio), moisture content, heating value and ash content [19].

Moisture affects the quality of pellets, which is set by national standards. For example, the European standard (European standard EN 14961 and its updates) classifies pellets into three categories, depending on the origin of the raw materials: (1) woody biomass - for which the moisture content is $\leq 10$; (2) herbaceous biomass - the moisture content is $<10$; (3) biomass from fruit and a mixture of the previous types of biomass - the moisture content is $\leq 15$ [20].

Therefore, to meet the standard level requirements, pellet moisture should be reduced after exiting the pellet press by immediately cooling of the hot fragile pellets from $95-100{ }^{\circ} \mathrm{C}$ to $25^{\circ} \mathrm{C}$, by means of forced air [21]. This results in increased hardness and durability of the pellets, and removal of fines.

The moisture content of biomass, when optimal, facilitating the heat transfer and helping in the thermal softening [7] acts like a binding agent, helping in self-bonding of individual particles [7] 
through the means of Van der Wall forces, thus increasing the contact area between the particles [22; 23]. Any further increase in the moisture content beyond the optimal value would reduce inter-particle forces; an even higher moisture content would result in a biphasic mixture (liquid and solid phases) and cause inter-particle forces to disappear entirely, leading to pellets swelling and disintegration [21; 24].

Moisture present in biomass facilitates starch gelatinization, protein denaturation and the processes of solubility during fiber extrusion [25; 26]. Steam treatment of biomass and additional heat modify the physic-chemical properties (starch gelatinization, protein denaturation) to such an extent that the bond between the particles is significantly increased, resulting in an improvement in compaction quality [27].

Dry wood is brittle and has low flexibility, when most of its water has been removed, and this could lead to high pelletizing pressure due to high friction. In the presence of water, inter and intra molecular hydrogen bonds between wood polymers are replaced with hydrogen bonds to water molecules. Water molecules act like a plasticizer, which increases biomass flexibility and softness, resulting in lower friction within the press channel. It is also possible that at lower temperature the presence of moisture enhances the migration of waxes or oils to the surface [3].

\section{Results and discussion}

Moisture contents in the range of 5-10\% are usually optimal for woody raw material. Moisture contents of $5 \%$ for olive tree wood [28] and of 6-8\% for pine wood [29] have been reported as appropriate for pelletizing. Corn stove pellets can be obtained from feedstock at high moisture content in the range of $28-38 \%$ (w.b.) by varying other process parameters [30]. During pelletizing, the moisture content of organic fibrous material can be in the range of $16-28 \%$, but the best results are obtained for the moisture content between 20-24\% [31]. Pellet-mill dies tend to choke, when the moisture content of the conditioned feedstock is 16-18\% (w.b.). During pelletizing, high fiber feeds cannot absorb moisture in the conditioning chamber, so water remains on the particle surface, causing excess particle-to-particle lubrication. The center of the pellet will extrude faster than the exterior, forming pellets with a "Christmas tree" shape, with reduced durability. At high moistures ( $\geq 25 \%$ w.b.), probably due to the incompressibility of water, moisture trapped within the particles may prevent complete flattening and the release of natural binders from the particles [7].

Tests carried out with moisture contents of $0 \%, 5 \%, 10 \%, 15 \%, 20 \%$ and $25 \%$ and die temperature of $20{ }^{\circ} \mathrm{C}$, revealed that for woody samples (beech and spruce particles, $1-3 \mathrm{~mm}$ in size) compressed at $200 \mathrm{MPa}$, an increase in the moisture content results in a decrease of the pelletizing pressure, which is more pronounced for beech than for spruce; for straws compressed under the same conditions as woody samples the pelletizing pressure increased with increasing moisture (Fig. 1). Pellet stability was best at 5-15\% moisture, while above $20 \%$ moisture no stable pellets were formed (Fig. 2). However, for completely dry biomass, pellet stability is very poor and a minimum amount of moisture is needed to improve the adhesion of particles [3].

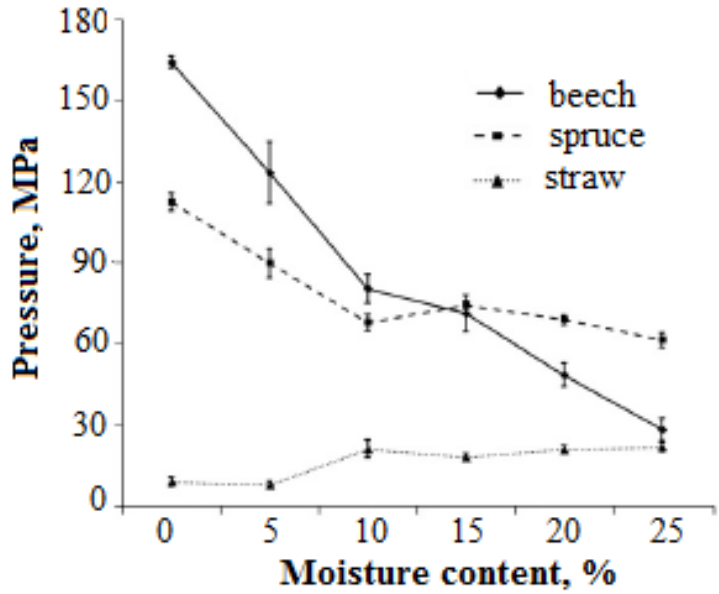

Fig. 1. Influence of moisture on pelletizing pressure at $20{ }^{\circ} \mathrm{C}[3]$
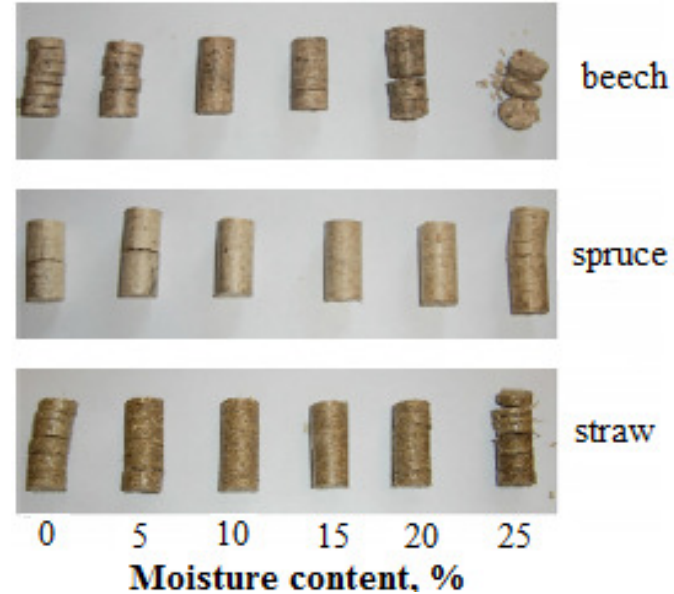

Fig. 2. Effect of moisture on pellet stability at $20^{\circ} \mathrm{C}$ [3] 
In other studies it was found that by increasing the moisture content of spruce sawdust from 7 to $15 \%$, the durability of pellets obtained increases significantly [32].

In papers $[33 ; 34]$ on the compaction of alfalfa, it was found that the largest die $(7.8 \mathrm{~mm}) \mathrm{can}$ withstand a moisture content of over $10 \%$, but the pellet durability after cooling decreases and the smaller die is blocked, when the moisture content of the materials exceeded $10 \%$.

A study conducted by Serrano et al. showed that the optimum moisture content for the production of dense barley straw pellets is in the range of $19-23 \%$, and there was no difference in pelletizing barley straws grounded with either 4 or $7 \mathrm{~mm}$ screen size. A durability of $95.5 \%$ was reached under these conditions, respectively $97-98 \%$, when small quantities of pine sawdust were added $(2,7$ and $12 \%$ of pine in straw). Agglomeration of the ground particles was improved by water and pine addition, while coarser grinding did not show any negative effect on barley straw compaction [24].

The effect of the moisture content on the durability of biomass pellets (corn stover, wheat straw, big bluestem BBS, and sorghum stalk PS) was investigated by [31]. Fig. 3 shows that the maximum durability value was $96.8 \%$ at the equilibrium moisture content range of $9 \%$ (d.b.) to $14 \%$ (d.b.) for corn stover and wheat straw, respectively $9 \%$ (d.b.) to $11 \%$ (d.b.) for big bluestem. A further increase in the moisture content resulted in the decrease of the pellet durability. For sorghum stalk pellets, the durability increased initially with increased moisture and reached a maximum of $89.5 \%$ at the moisture values between $14 \%$ (d.b.) and $16 \%$ (d.b.).

In general, the density and durability of the pellets is the reverse proportional to the particle size, because smaller particles have a larger surface during the densification process [22]. In studies on alfalfa [35], it was found that medium or fine sized materials are desirable because in the compaction process, at these sizes, they have larger areas of moisture during steam conditioning, which results in increased starch gelatinization.

Said et al. [20;36] used rice straw grinded to $4 \mathrm{~mm}$ particle size and maize starch as a binder to produce pellets in a flat die pelletizing press, with variable biomass moisture $(12 \%, 15 \%$ and $17 \%)$ and temperature inside the press produced by the friction between the straws, in the range of $20^{\circ} \mathrm{C}$ to $80^{\circ} \mathrm{C}$ (above which pellets could not be produced). Moisture content of the pellets ranged from $10.12 \%$ to $16.33 \%$, values that were on the "safe storage" side of the $20 \%$ threshold preventing bacterial growth [37], material degradation and self heating, which in the worst case scenario could result in self-ignition [38]. The high values of pellet moisture are due to the high moisture content of rice straws necessary for pelletizing, as well as the low temperature range, under which the pellets were produced.

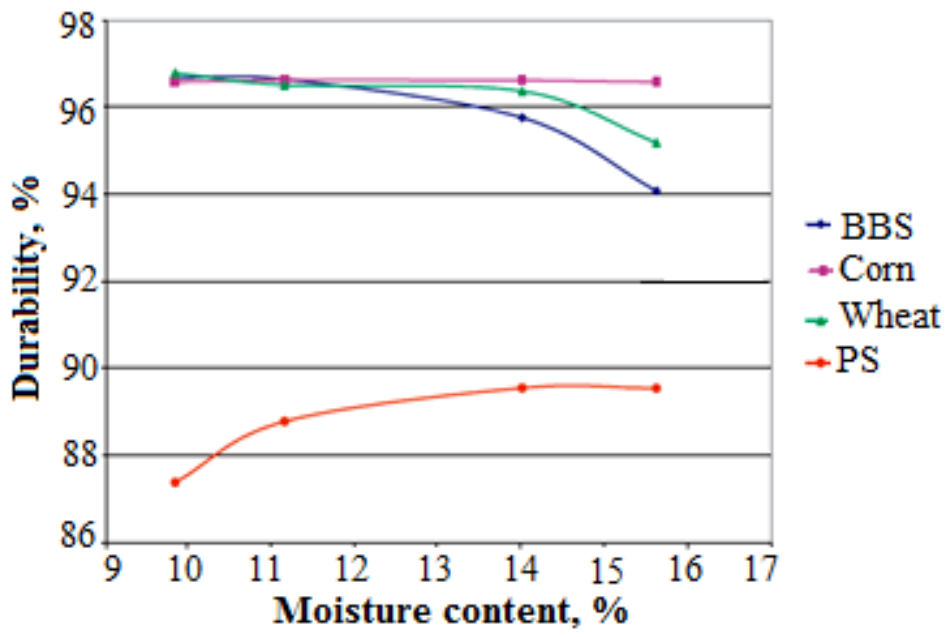

Fig. 3. Dependency between moisture and pellet durability [20]

Unpit et. al. [15] investigated the water impermeability of pellets prepared from six types of biomass: bamboo sawdust (14\% w.b.), eucalyptus sawdust (9.1\% w.b.), corn cob (9.14 \% w.b.), rubber tree branches (10.9\% w.b.), palm fiber (9.9\% w.b.) and lippia grass ( $8.1 \%$ w.b.). These materials were milled into small particles (less than $5 \mathrm{~mm}$ ) before binderless pelletizing at ambient 
temperature with maximum load of $555 \mathrm{MPa}$. The most dense pellet was obtained from bamboo sawdust, whereas pellets prepared from corn cob were the most loose. From Fig. 4, showing the influence of compaction pressure on water impermeability of pellets, it can be noticed that by increasing the pressure from 56 to $139 \mathrm{MPa}$, water impermeability decreased to the minimum value and then slightly increased at a higher pressure. For the same compaction pressure, the corn cob pellet has the highest water impermeability due to the stronger water absorbing power of corn cobs. Pellets prepared from bamboo sawdust and eucalyptus sawdust had small differences in water impermeability.

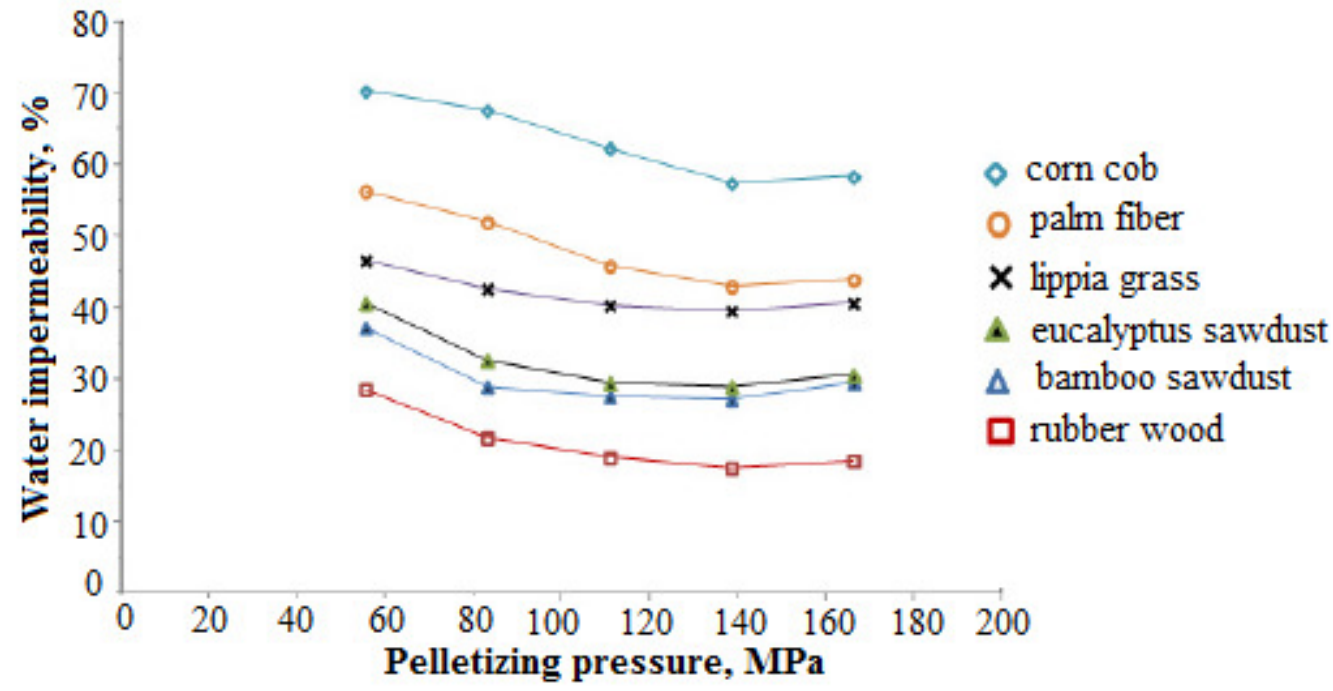

Fig. 4. Influence of pelletizing pressure on pellet impermeability to water [15]

In study [39], the raw materials used to produce pellets were sawdust and rapeseed cake. The wet sawdust had the moisture content of $52-60 \%$ and it was dried at $200-220{ }^{\circ} \mathrm{C}$ to reach a moisture content of 10-14.4\%. Additionally, rapeseed cake with the moisture content of 6.6-7.3\% was mixed with the sawdust. Die pressure was set at a constant of 8.5 MPa. The results showed that a moisture content of about $14 \%$ in the raw material is needed, if good quality pellets with the moisture content of about $6-8 \%$ are to be produced.

Munawar and Subiyanto [40] used as feedstock oil palm empty fruit bunch (OPEFB), oil palm frond (OPF), oil palm shell (OPS) and oil palm mesocarp (OPM), compressed at temperatures of 150, 200 and $250^{\circ} \mathrm{C}$ for 15 minutes. The highest water content $(5.8 \%)$ resulted for OPEFB pellet compressed at $250{ }^{\circ} \mathrm{C}$ and the lowest one resulted for OPF (1.5\%) compressed at $200{ }^{\circ} \mathrm{C}$ (Fig. 5).

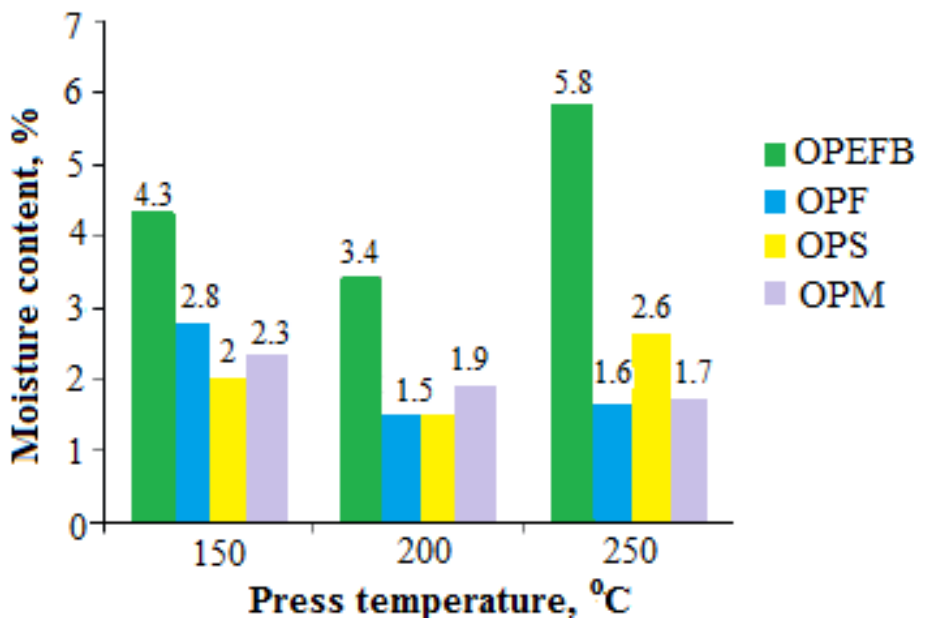

Fig. 5. Effect of press temperature on moisture content of pellets [40]

From all formulas, OPM pellets showed the lowest water content, when compared with other materials. Lower water content makes pellet combustion easier and the storage life becomes longer, while high water content can cause mold growth during storage [40]. 
The tests carried out on pellets obtained from rice straws with particle sizes of 5,10 and $20 \mathrm{~mm}$, at forming temperatures of 60,80 and $100{ }^{\circ} \mathrm{C}$ and the initial moisture content between $15-20 \%$ revealed that the optimal moisture content for a high calorific power was between 13-20\% under forming temperature of 60 or $80{ }^{\circ} \mathrm{C}$. With the initial moisture content of $15 \%$ and forming temperatures of 60 or $80^{\circ} \mathrm{C}$, rice straw pellets were formed with a high yield ratio and high durability [41; 42].

$\mathrm{Li}$ and Liu (2000) investigated the compaction of tree bark, waste resulting from timber production, wood chips, dried alfalfa (hay), fresh alfalfa and grass, as a moisture content of about $8 \%$ was optimal to produce high density pellets. They recommended that a moisture content of $5-12 \%$ is required to produce a good quality product (in terms of optimal density and properties on long term deposit) [43]. Also, the fact that the pellets tend to become fragile in just a few days after their production, if the moisture content used is less than $4 \%$, is due to moisture absorption from the environment [44].

In other experimental studies it has been found that the optimum moisture content for pelletization of cellulosic materials is $8-12 \%$, while for materials containing starch and protein, the moisture can reach up to $20 \%$ [45; 46; 47].

\section{Conclusions}

1. Due to the threat of climate change, the need to reduce the emissions of greenhouse gases and increasing of oil prices, it became imperative to increase the use of biomass in energy production.

2. Biomass densification is an efficient technology to achieve the target of the biomass resource utilization. Biofuel pellets can be manufactured from various types of largely available biomass feedstock, including wood wastes, agricultural residues, industrial by-products and energy crops.

3. In the analyzed scientific papers on compaction of biomass it is demonstrated that the raw material variables (moisture content, particle size and shape) and the biochemical composition of biomass - proteins, fats, cellulose, hemicellulose and lignin, as well as the process variables such as the die temperature, pressure and die geometry, play a major role in the quality of compacted biomass.

4. Moisture content of pellets is strongly related to their physical properties and for quality products it should be in the range between 10-15\%. Determination of the optimum moisture content of pellets, which varies by biomass type, is necessary for production of pellets with high stability and durability, and also for selection of suitable storage conditions.

\section{Acknowledgements}

This work was funded by the Executive Agency for Higher Education, Research, Development and Innovation Funding, within the project entitled "Optimizing the composition of biomass mixtures for obtaining high quality pellets", ctr. 24 BG / 2016 (code PN-III-P2-2.1-BG-2016-0266), Romania.

\section{References}

[1] Bridgwater A. V. Review of fast pyrolysis of biomass and product upgrading. Biomass Bioenergy, vol. 38, 2012, pp. 68-94.

[2] Stelte W., Holm J. K., Sanadi A. R., Barsberg S., Ahrenfeldt J., Henriksen U. B. Fuel pellets from biomass: the importance of the pelletizing pressure and its dependency on the processing conditions. Fuel, vol. 90, 2011, pp. 3285-3290.

[3] Mola-Yudego B., Selkimäki M., González-Olabarria J.R. Spatial analysis of the wood pellet production for energy in Europe. Renewable Energy, vol. 63, 2014, pp. 76-83.

[4] Castellano J. M., Gomez M., Fernandez M., Esteban L. S., Carrasco J. E. Study on the effects of raw materials composition and pelletization conditions on the quality and properties of pellets obtained from different woody and non woody biomasses. Fuel, vol. 139, 2015, pp. 629-635.

[5] Karwandy, J. Pellet production from sawmill residue: a Saskatchewan perspective. Forintek Canada Corp Report. No. 2006-29, 2007.

[6] Kaliyan N., Morey R. V. Factors affecting strength and durability of densified biomass products. Biomass Bioenergy, vol. 33, 2009, pp. 337-359.

[7] Graham S., Eastwick C., Snape C., Quick W. Mechanical degradation of biomass wood pellets during long term stockpile storage. Fuel Processing Technology, vol. 160, 2017, pp. 143-151. 
[8] Nunes J., Freitas H. An indicator to assess the pellet production per forest area. A case-study from Portugal. Forest Policy and Economics, vol. 70, 2016, pp. 99-105.

[9] Vinterbäck, J. Wood Pellet Use in Sweden: A Systems Approach to the Residential Sector (PhD thesis) Swedish University of Agricultural Sciences, 2000. Umeå, Sweden.

[10] Sikkema K., Steiner M., Junginger M., Hiegl W., Hansen M., Faaij A. The European wood pellet markets: current status and prospects for 2020. Biofuels Bioprod. Biorefin., vol. 5, 2011, pp. 250-278.

[11]Duca D., Riva G., Foppa Pedretti E., Toscano G. Wood pellet quality with respect to EN 14961-2 standard and certifications. Fuel, vol 135, 2014, pp. 9-14.

[12] Laschi A., Marchi E., Gonzales-Garcia S. Environmental performance of wood pellets' production through life cycle analysis. Energy, vol. 103, 2016, pp. 469-480.

[13] Kofman P. D. Simple ways to check wood pellet quality. Coford Connect, vol. 11, 2007, pp. 8-9.

[14] Unpinit T., Poblarp T., Sailoon N., Wongwicha P., Thabuot M. Fuel properties of bio-pellets produced from selected materials under various compacting pressure. Energy Procedia, vol. 79, 2015, pp. 657-662.

[15] Samuelsson R., Larsson S. H., Thyrel M., Lestander, T. A. Moisture content and storage time influence the binding mechanisms in biofuel wood pellets. Applied Energy, vol. 99, 2012, pp. $109-115$.

[16] Vladut V., Chitoiu M., Danciu A., Militaru M., Lehr C. The importance of humidity on agricultural and forestry biomass in the process of pellets and agri-pellets production. Bulletin USAMV Agriculture, vol. 67, no. 1, 2010, pp. 292-300.

[17] Caroll J. P., Finnan J. Physical and chemical properties of pellets from energy crops and cereal straws. Biosystems Engineering, vol. 112, 2012, pp. 151-159.

[18] García-Maraver A., Popov V., Zamorano M. A review of European standards for pellet quality. Renewable Energy, vol. 36, 2011, pp. 3537-3540.

[19] Garcia-Maraver A., Popov V., Zamorano M. A review of European standards for pellet quality. Renewable Energy, vol. 36, 2011, pp. 3537-3540.

[20] Said N., Abdel Daiem M. M., Garcia-Maraver A., Zamorano M. Influence of densification parameters on quality properties of rice straw pellet. Fuel Processing Technology, vol. 138, 2015, pp. 56-64.

[21] Serrano C., Monedero E., Lapuerta M., Portero H. Effect of moisture content, particle size and pine addition on quality parameters of barley straw pellets, Fuel Process. Technol., vol. 92, no. 3, 2011, pp. 699-706.

[22] Tumurulu J.S., Wright C.T., Kevin K.L., Hess J.R. A Review On Biomass Densification Technologies To Develop Uniform Feedstock Commodities For Bioenergy Application. BioFPR, 2011. The INL is a U.S. Department of Energy National Laboratory operated by Battelle Energy Allianc, INL/EXT-10-18420.

[23] Sastry K. V. S , Fuerstenau D. W. Mechanisms of Agglomerate Growth in green Pellitization. Powder Technology, vol. 7, 1973, pp. 97-105.

[24] Carone M. T., Pantaleo A., Pellerano A. Influence of process parameters and biomass characteristics on the durability of pellets from the pruning residues of Olea europaea L. Biomass Bioenerg., vol. 35, 2011, pp. 402-410.

[25] Shaw M. Feedstock and Process Variables Influencing Biomass Densification, Ph.D. thesis submitted to Department of Agricultural and Bioresource Engineering, University of Saskatchewan, 2008.

[26] Voicea I., Voicu Gh. Cardei P. Vladut V., Gageanu I., Daraban A. Theoretical and experimental research on the process of biomass briquetting. U.P.B. Sci. Bull., Series D, vol. 78, no. 3, 2016, pp. 203-214.

[27] Thomas M., van Zuilichem D. J., van der Poel A. F. B. Quality of Pelleted Animal Feed 2. Contribution of Processes and its Conditions, Animal Feed Science Technology, vol. 64, 1997, pp. 173-192.

[28] Nielsen N. P. K., Gardner D. J., Poulsen T., Felby C. Importance of temperature, moisture content, and species for the conversion process of wood residues into fuel pellets. Wood Fiber Sci., vol. 41, no. 4, 2009, pp. 414-425. 
[29] Tumuluru J. S. Effect of process variables on the density and durability of the pellets made from high moisture corn stover. Biosyst. Eng., vol. 119, 2014, pp. 44-57.

[30] Nguyen Q. N., Cloutier A., Achim A., Stevanovic T. Effect of process parameters and raw material characteristics on physical and mechanical properties of wood pellets made from sugar maple particles. Biomass and Bioenergy, vol. 80, 2015, pp. 338-349.

[31] Theerarattananoon K., Xu F., Wilson J., Ballard R., Mckinney L., Staggenborg S., Vadlani P., Pei Z. J., Wang D. Physical properties of pellets made from sorghum stalk, corn stover, wheat straw, and big bluestem. Industrial Crops and Products, vol. 33, 2011, pp. 325-332.

[32] Matúš M., Križan P. Influence of structural parameters in compacting process on quality of biomass pressings. Journal of applied mathematics. vol. 3, no. 3, 2010, pp. 87-96.

[33] Tabil L. G., Sokhansanj S. Process Conditions Affecting the Physical Quality of Alfalfa Pellets. American Society of Agricultural Engineers, vol. 12, no. 3, 1996. pp. 345-350.

[34] Tabil Jr., L. G. Binding and Pelleting Characteristics of Alfalfa. Ph.D. Thesis, 1996. Saskatoon, Saskatchewan: Department of Agricultural and Bioresource Engineering, University of Saskatchewan.

[35] Payne J. D. Quality of Pellet Feeds, Milling Feed and Fertilizer, vol. 161, 1978, pp. 34-41.

[36] Lehtikangas P. Storage effects on pelletised sawdust, logging residues and bark. Biomass Bioenergy, vol. 19, 2000, pp. 287-293.

[37]Rhén C., Gref R., Sjöström M., Wästerlund I. Effects of raw material moisture content, densification pressure and temperature on some properties of Norway spruce pellets. Fuel Process. Technol., vol. 87, 2005, pp. 11-16.

[38] Stahl M., Berghel J. Energy efficient pilot-scale production of wood fuel pellets made from a raw material mix including sawdust and rapeseed cake. Biomass and Bioenergy, vol. 35, 2011, pp. 4849-4854.

[39] Sofyan Munawar S., Subiyanto B. Characterization of biomass pellet made from solid waste oil palm industry. Procedia Environmental Sciences, vol. 20, 2014, pp. 336-341.

[40] Ishii K., Furuichi T. Influence of moisture content, particle size and forming temperature on productivity and quality of rice straw pellets. Waste Management, vol. 34, 2014, pp. 2621-2626.

[41] Voicea I, Vladut V., Cardei P., Matache M., Gageanu I., Voicu Gh., Popescu C, Paraschiv G., Kabas O. Compacting process and mathematical analysis of Mischantus briquettes expansion. 43 Symposium “Actual Tasks on Agricultural Engineering”, Opatija, Croatia, 2015, pp. 667-676.

[42] Li Y., Liu H. High pressure densification of wood residues to form an upgraded fuel. Biomass and Bioenergy, vol. 19, 2000, pp. 177-186.

[43]Liu C., Wyman C. E. Partial flow of compressed-hot water through corn stover to enhance hemicellulose sugar recovery and enzymatic digestibility of cellulose. Bioresource Technology, vol. 96, 2005, pp. 1978-1985.

[44] Li J. F., Hu R. Q. Sustainable Biomass Production for Energy in China. Biomass Bioenergy, vol. 25, 2003. pp. 483-499.

[45]Liu C., Wyman C. E. Partial Flow of Compressed-Hot Water Through Corn Stover to Enhance Hemicellulose Sugar Recovery and Enzymatic Digestibility of Cellulose. Bioresource Technology, vol. 96, 2005, pp. 1978-1985.

[46] Sokhansanj S., Mani S., Bi X., Zaini P., Tabil L. Binderless Pelletization of Biomass, Presented at the ASAE Annual International Meeting, Tampa, FL, ASAE Paper No. 056061. 2950 Niles Road, St. Joseph, MI 49085-9659 USA, 2005.

[47] Voicea I. Research regarding optimization of biomass compaction process. PhD thesis, 2016. University Politehnica of Bucharest, Romania. 